\title{
Linking ecosystem services and human-values theory
}

\author{
Christina C. Hicks, ${ }^{*}+\uparrow$ Joshua E. Cinner, $\uparrow$ Natalie Stoeckl, $\ddagger$ and Tim R. McClanahan $₫$ \\ ${ }^{*}$ Center for Ocean Solutions, Stanford University, Monterey, CA 93940, U.S.A. \\ tARC Centre of Excellence for Coral Reef Studies, James Cook University, Townsville, QLD 4811, Australia \\ $\ddagger$ School of Business, James Cook University, Townsville, QLD 4811, Australia \\ §Wildlife Conservation Society, Marine Programs, Bronx, NY 10460, U.S.A.
}

\begin{abstract}
Understanding why people make the decisions they do remains a fundamental challenge facing conservation science. Ecosystem service (ES) (a benefit people derive from an ecosystem) approaches to conservation reflect efforts to anticipate people's preferences and influence their environmental behavior. Yet, the design of ES approaches seldom includes psychological theories of human behavior. We sought to alleviate this omission by applying a psychological theory of human values to a cross-cultural ES assessment. We used interviews and focus groups with fish workers from 28 coral reef fishing communities in 4 countries to qualitatively identify the motivations (i.e., human values) underlying preferences for ES; quantitatively evaluate resource user ES priorities; and identify common patterns among ES motivations and ES priorities (i.e., trade-offs and synergies). Three key findings are evident that align with buman values theory. First, motivations underlying preferences for individual ESs reflected multiple buman values within the same value domain (e.g., self-enbancement). Second, when averaged at community or country scales, the order of ES priorities was consistent. However, the order belied significant variation that existed among individuals. Third, in line with human values theory, ESs related to one another in a consistent pattern; certain service pairs reflected trade-off relationships (e.g., supporting and provisioning), whereas other service pairs reflected synergistic relationships (e.g., supporting and regulating). Together, these findings belp improve understanding of when and why convergence and trade-offs in people's preferences for ESs occur, and this knowledge can inform the development of suitable conservation actions.
\end{abstract}

Keywords: cultural psychology, human behavior, motivations, social psychology, synergy, trade-off

Enlazando los Servicios Ambientales y la Teoría de Valores Humanos

Resumen: Entender por qué las personas toman las decisiones que toman todavía es un obstáculo fundamental que encara la ciencia de la conservación. Las estrategias de conservación basadas servicios ambientales (SA) (beneficios que las personas obtienen de un ecosistema) reflejan los esfuerzos por anticiparse a las preferencias de las personas e influir sobre su comportamiento bumano. A pesar de esto, el diseño de las estrategias de SA casi nunca incluyen las teorías psicológicas del comportamiento bumano. Buscamos aliviar esta omisión al aplicar una teoría psicológica de valor bumano a la evaluación trans-cultural de los SA. Utilizamos entrevistas y grupos de muestreo con pescadores de 28 comunidades de pesca en arrecifes de coral en cuatro países para identificar cualitativamente las motivaciones (es decir, los valores bumanos) que subyacen las preferencias por los SA; evaluar cualitativamente las prioridades de SA de los usuarios de los recursos; e identificar los patrones comunes entre las motivaciones y las prioridades de los SA (es decir, las compensaciones y las sinergias). Tres hallazgos clave que se alinean con la teoría de valor bumano son evidentes. Primero, las motivaciones que subyacen las preferencias para los SA individuales reflejaron múltiples valores bumanos dentro del mismo dominio de valor (por ejemplo, el auto-mejoramiento). Segundo, al promediar el orden de las prioridades de SA a escala de comunidad o de país, este fue congruente. Sin embargo, el orden contradijo una variación significativa que existió entre los individuos. Tercero, en línea

|Address for correspondence: ARC Centre of Excellence for Coral Reef Studies, James Cook University, Townsville, QLD 4811, Australia, email christina.c.bicks@gmail.com

Paper submitted April 30, 2014; revised manuscript accepted March 3, 2015.

This is an open access article under the terms of the Creative Commons Attribution-NonCommercial License, which permits use, distribution and reproduction in any medium, provided the original work is properly cited and is not used for commercial purposes. 
con la teoría de valor bumano, los SA se relacionaron unos con otros en un patrón congruente; ciertos pares de servicios reflejaron las relaciones de compensación (por ejemplo, sustentación y provisión), mientras que otros pares de servicios reflejaron las relaciones sinérgicas (por ejemplo, sustento y regulación). En conjunto, estos hallazgos ayudan a mejorar el entendimiento de cuándo y por qué ocurren la convergencia $y$ las compensaciones en las preferencias de las personas por los SA, y este conocimiento puede informar al desarrollo de acciones de conservación apropiadas.

Palabras Clave: compensación, comportamiento humano, motivaciones, psicología cultural, psicología social, sinergia

\section{Introduction}

Despite local, national, and global efforts to mitigate undesirable ecosystem change (COP 2011), anthropogenic impacts on Earth's systems are intensifying (Barnosky et al. 2012; Costello et al. 2012). This widespread failure to steer human behavior has brought with it a growing recognition that the solutions to environmental challenges need to transcend disciplinary boundaries and, specifically, incorporate social considerations (Daily \& Matson 2008; Milner-Gulland 2012). In response, the Millennium Ecosystem Assessment (MA 2003) endorsed an ecosystem services (ESs) approach that explicitly recognizes the benefits people gain from nature. By describing how nature is a benefit to people, the ES approach aims to align environmental sustainability with human well-being and thus build support for conservation and sustainable resource management (Daily 1997; Norgaard 2010).

Although there is an explicit focus on steering human behavior toward a more sustainable path, ES applications have to date largely come from the ecological or economic sciences (e.g. Balvanera et al. 2006; Mace et al. 2011; Bateman et al. 2013) and lacked integration with the broader social science literature about people's choices and behavior (Ajzen 1991; Milner-Gulland 2012; Schwartz 2013). However, a growing body of conservation-focused research that draws on the psychological sciences can help to inform these efforts. This research seeks to determine how people's environmental choices and behaviors are shaped by their values, beliefs, attitudes, norms, and intentions (Ajzen 1991; Stern et al. 1999; Manfredo et al. 2009). These factors, in various combinations, are used in frameworks such as a theory of planned behavior (Ajzen 1985, 1991) and value belief norm (Stern et al. 1999) to predict specific behaviors, such as maintaining a forest patch or recycling (Mastrangelo et al. 2014). In all cases, human values, which are an expression of people's motivational goals (Schwartz 1994; Rokeach 2008), are antecedent to the factors that shape their behavior (Stern et al. 1999; Song et al. 2013). Yet, few studies have explicitly examined how human values, and thus behaviors, are related to people's ES preferences.

It is generally accepted that a small number of human values exist, are present in all societies, and are prioritized in a consistent order (Schwartz 1994; Rokeach 2008; Hofstede 2011). Because this finite set of values are conceptually consistent, scholars have been able to develop robust value-measurement systems that advance and validate ideas about human values and how they relate to one another (e.g., Morris 1956; Rokeach 2008; Schwartz 2013). For example, in a widely adopted framework, Schwartz (1994, 2013) identified 10 basic human value types (benevolence, universalism, self-direction, stimulation, hedonism, achievement, power, security, tradition, conformity) that are related to each other, heuristically depicted as a wheel of values (Schwartz 1994, 2013) (Fig. 1a; Supporting Information). Within this wheel, adjacent values have similar motivations and differences are accentuated when values are opposite each other. These 10 values cluster into 4 domains (traditionalism, openness to change, self-transcendence, self-enhancement) that lie along 2 axes (Table 1). Values within a domain complement one another and domains that lie in opposition to one another create potential trade-offs, where activities that enhance values in one domain will obstruct values in the opposing domain (Schwartz \& Bardi 2001; Davidov 2010). Behaviors are therefore guided by trade-offs among competing values such that people will actively oppose activities that enhance low priority values and promote activities that enhance high priority values (Rokeach 1973; Tetlock 1986; Schwartz 1996). Self-enhancement values lie opposite self-transcendence values and reflect a trade-off between concern for self and concern for others. Openness-to-change values lie opposite traditionalism values, reflecting a trade-off between desires for change and for stability. Therefore, an understanding of the human values associated with various ES preferences can help managers and scientists anticipate people's general behavior (e.g., tendency to cooperate or not) (Schwartz 1996).

We positioned marine ESs (MA 2003; Böhnke-Henrichs et al. 2013) in a human values framework (Schwartz 1994, 2013) to improve understanding of the underlying values associated with specific ES preferences. To operationalize this, we visited 28 coral reef fishing communities in 4 countries to examine how resource users' prioritize nine ES and the human values associated with each. We sought to determine how resource users conceptualized ES benefits, the human values associated with ES 


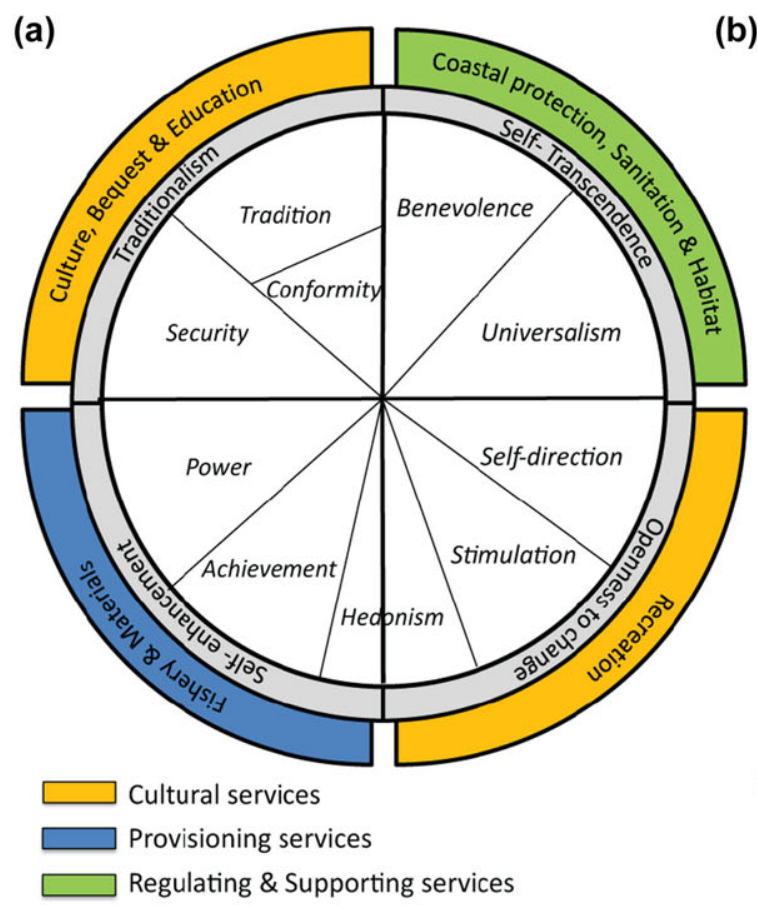

(b) 2D Stress: 0.16

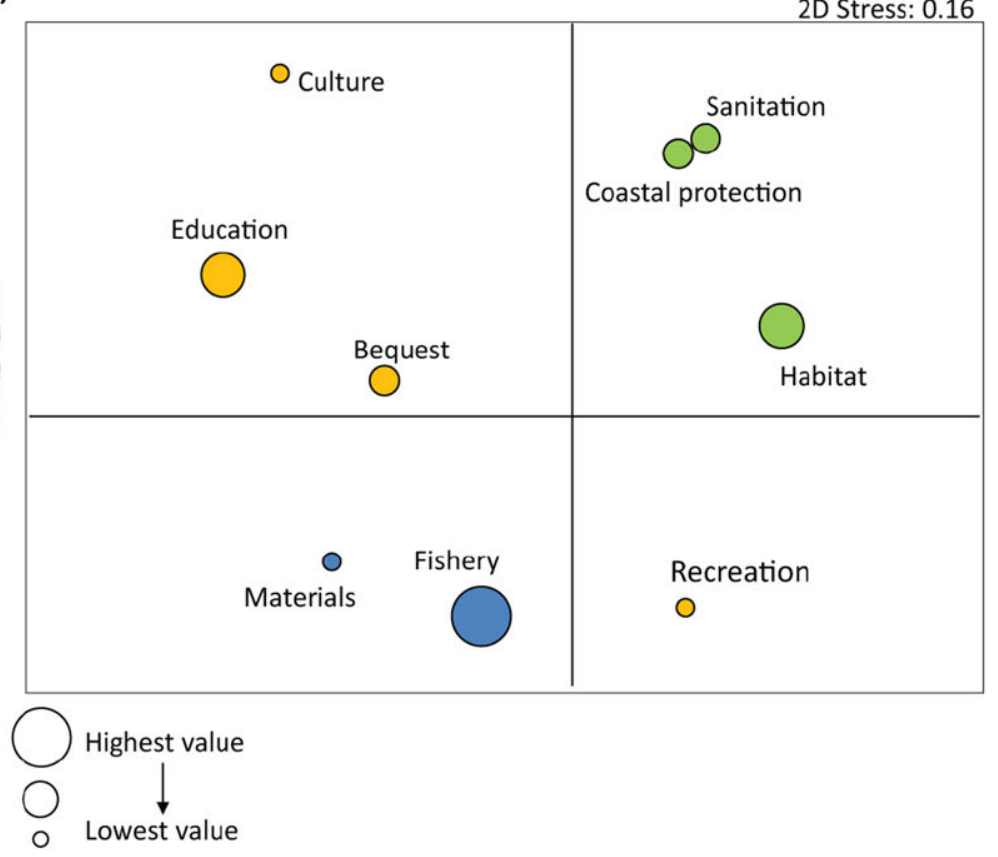

Figure 1. Ecosystem service value orientations: (a) Human values wheel (2 circles) adapted from Schwartz (1994), showing human values and how they are structurally related to each other (values adjacent to one another are similar and values opposite one another are in opposition; outer circle, placement of identified ecosystem services according to motivations underlying resource users ES preferences [Table 2, Supporting Information]) and (b) similarities between quantitative ecosystem service priorities (for marginal values).

preferences, how resource users prioritized ES benefits, and how ESs (i.e., their associated human values and priorities) related to one another (i.e., which ESs create synergies and which trade-offs).

\section{Methods}

We conducted interviews and focus groups with fish workers (fishers, fish processors, and traders) from 28 independent coral reef fishing communities across Kenya, Tanzania, Madagascar, and Seychelles. Communities were selected to be representative of the regions rural coral reef fishing communities. These fisheries were therefore artisanal (i.e., small scale), where fishers land a diversity of reef and reef-associated species for home consumption and local markets using a diversity of gears (broadly classified as spears, nets, traps, and handlines).

For each community, we contacted the relevant local fish workers organization or the fisheries department to establish how many registered fish workers they were, how old they were, where they lived, and what they used as a primary gear. We used this information to randomly select respondents across the age, gear, and geographic range of all involved in the fishery. Informed consent was obtained from all participants. Fish workers were predominantly male, although there were some female fish processors and traders. The average age of a fish worker was 40 years (range 14-80).

We conducted 28 focus groups, one in each community, at either fish landing sites, communal meeting spots, or a fisher's house. Focus groups were designed to help us conceptualize ES benefits and identify the underlying motivations (i.e., human values) associated with these benefits. We then conducted face-to-face, individual, semi-structured interviews to quantitatively measure resource users' ES priorities according to how important each ES was to each resource user. We interviewed 374 fish workers, 7-32 from each community, which represented $20-40 \%$ of the fish workers in each community (Hicks et al. 2013).

\section{Conceptualizing ES benefits and underlying values}

We asked resource users in focus groups to explore the benefits they associated with their environment (Hicks et al. 2013; Hicks \& Cinner 2014). We then used concepts from an ecological economics perspective on ES (MA 2003; Supporting Information) to stimulate further discussion and determine whether any ES, relevant to resource users across the 4 study countries, had been missed. The first 2 focus groups in each country developed a description of each ES and selected a photograph of each ES to be used later in the quantitative strategy 


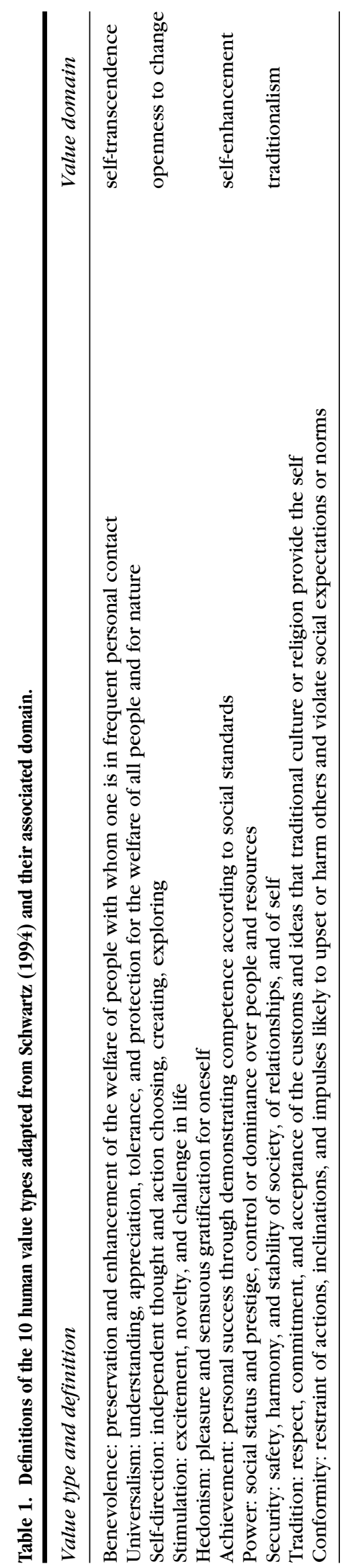

(described below). The later focus groups were used to ensure the descriptions and photographs (Supporting Information, Hicks et al. 2013) were applicable at different sites, where necessary adjustments were made. For example, some communities identified the spiritual significance of a baobab tree (Adansonia spp.) (a cultural service), whereas others identified spiritual sites found in coastal caves, known as kayas. The final list contained 9 ESs that we categorized into 1 of the 4 ES categories: provisioning services- fishery and materials; regulating services- coastal protection and sanitation; supporting service- habitat provision; and cultural serviceseducation, recreation, culture, and bequest (natural or cultural heritage for future generations).

In the second part of the focus group, we used a human values framework (Schwartz 1994, 2013) from social psychology to identify the underlying motivations (i.e., human values) associated with each benefit. We asked resource users to explore and articulate why each of the nine ES were important in their lives. The first author used the notes and transcripts from the focus groups to code respondents' statements according to statements used in Schwartz (2009) value survey (SVS). The SVS contains 58 statements (e.g., preserving my image) that are associated with a specific value type (e.g., power). The SVS allowed us to assign a value type or types to respondent's statements and thus to assign a value to each ES. For example, respondents said fishery benefits were important because acquiring them enabled fishers to gain personal income; provide for families; be seen as a skilled fisher; and eat tasty fish. These motivations reflected the following statements from the SVS "wealth- material possessions and money"; "influential- having an impact on people and events"; "preserving my image- protecting my face"; and "pleasure- gratification of desire" that reflect power, achievement, and hedonism values. Fishery was therefore assigned power, achievement, and hedonism values, which fall within the self-enhancement domain (Table 1, Table 2, Supporting Information). The last author then independently checked the first author's assignment of value types to ES. Where inconsistencies arose, the first author revisited the original text and decided which value type most closely reflected the respondents' statements.

\section{Quantifying ES priorities}

In the quantitative component of the evaluation, we used individual semi-structured interviews to estimate the relative importance individuals assigned to each ES. We were interested in how important the ES was in general (often referred to as total value) and how important it was to enhance or increase the ES (often referred to as marginal value) (Pearce $\&$ Turner 1989; Bateman et al. 2002). Total and marginal values are quite distinct. For example, in general water tends to be very important because it is 
Table 2. Ecosystem services, the motivations underlying their preferences, the associated human value types, and domain.

\begin{tabular}{|c|c|c|c|}
\hline Sanitation & $\begin{array}{l}\text { safe and clean water for the community and } \\
\text { environment }\end{array}$ & $\begin{array}{l}\text { benevolence and } \\
\text { universalism }\end{array}$ & self-transcendence \\
\hline Coastal protection & a safe fishing environment, safety for homes & & \\
\hline Habitat & $\begin{array}{l}\text { maintaining ecosystem function to ensure } \\
\text { continued productivity and provision of all } \\
\text { ecosystem benefits for the ecosystem and } \\
\text { for others in the community }\end{array}$ & universalism & \\
\hline Recreation & $\begin{array}{l}\text { harnessing ecosystem qualities for new income } \\
\text { opportunities (e.g. potential to take tourists } \\
\text { snorkeling to see corals and fish); embracing } \\
\text { and exploring new sources of income; a } \\
\text { new economy; and fast paced lifestyle }\end{array}$ & $\begin{array}{l}\text { self-direction, } \\
\text { stimulation, and } \\
\text { hedonism }\end{array}$ & openness to change \\
\hline Fishery & $\begin{array}{l}\text { harnessing the ecosystem for income and food; } \\
\text { being a skilled fisherman; enjoying a fishers } \\
\text { lifestyle }\end{array}$ & $\begin{array}{l}\text { hedonism, achievement, } \\
\text { and power }\end{array}$ & self-enhancement \\
\hline Culture & $\begin{array}{l}\text { maintaining traditions, beliefs, behaving } \\
\text { appropriately }\end{array}$ & & \\
\hline Education & $\begin{array}{l}\text { creating or maintaining responsible and } \\
\text { effective fishing practices }\end{array}$ & & \\
\hline
\end{tabular}

a Millennium ecosystem assessment (MA 2003).

${ }^{b}$ Statements from focus groups (Supporting Information).

${ }^{c}$ Schwartz (1994) value types and value domains.

necessary for survival. But, an increase in available water is only likely to be important for people who do not currently have enough water.

In the interviews, we used the photographs and descriptions of the ES (Hicks et al. 2013; Supporting Information) to discuss and reach a common understanding of each ES with respondents. We then asked the respondents to rank the services by arranging the photographs in order of how important each ES was to them in general. The ranking exercise generated ordinal data that reflected an estimate of total value. It is, however, important to recognize that ranking forces an order; therefore, it is not possible for two services to be viewed as equally important, if they are. Next, we asked the respondents to rate the services by how important it was to gain an increase from each service (e.g., a more productive fishing trip, a healthier reef, more spiritual fulfillment from cultural practices). For the rating exercise, fishers were provided with 20 matches and asked to distribute the matches across the nine ES, according to where they would most like to see an increase in the quantity or quality of that service. For example, respondents could place all matches on one particular service or distribute them among several services. To maximize the time spent considering where matches were distributed and allow respondents to reevaluate their distributions, we provided the 20 matches in 4 batches. The number of batches and weighting applied to a match from each batch was determined separately (for details, see Supporting Infor- mation). The rating exercise generated continuous data that reflected an estimate of marginal value. We normalized the importance (marginal and total) of ES to a common, continuous scale of $0-1$ across all ecosystem services:

$$
x_{\text {norm }}=\frac{\left(x-x_{\min }\right)}{\left(x_{\max }-x_{\min }\right)} .
$$

\section{Ordering of ES priorities}

We used a linear mixed model (LMM) (Field 2009) that tests for differences in ES priorities (for marginal and total values separately) followed by post hoc pair-wise comparisons of the 9 ESs to see where differences lie. This allowed us to determine whether there is a consistency in the ordering of ES priorities that holds across scale - similar to that found for human values. We ran 3 separate models that first accounted for intercountry variation; second accounted for intercommunity variation; and, third did not account for intercountry or intercommunity variation. We fitted all models and compared Akaike information criterion values (AIC) to select the best model fit (Supplementary Information).

We next used a LMM (Field 2009) to test for differences in individuals' priorities (for marginal and total values separately) followed by a linear regression of variability (measured as standard deviation) against priority, to determine where the greatest variability lies across a gradient of priorities. We again ran 3 separate models that first 
accounted for intercountry variation; second accounted for intercommunity variation; and, third did not account for intercountry or community variation (Supplementary Information). We again fitted all models and compared AIC values to select the best model fit. For all models, we checked assumptions of normality and homogeneity by visual inspection of residual plots. Data were homogenous but displayed some departure from normality for marginal values; however, while LMM is sensitive to problems with homogeneity, it is considered robust to departures of normality (Mass \& Hox 2004).

\section{Relationships among ESs}

To determine how ESs are related to one another (i.e., whether certain services create synergies and others trade-offs), we used the 3 independent data sets (i.e., ES human values, marginal ES priorities, total ES priorities) to map and visually compare the similarities among ESs. We used the data sets in 3 ways. First, we used the human values associated with each ES, identified from the focus groups, to arrange the 9 ESs around Schwartz's (1994, 2013) value wheel (Table 2) (Fig. 1a). The Schwartz wheel arranges values with similar motivations close together and values with opposing motivations at a distance. Second, we used respondents marginal ES priorities, determined in the rating exercise, to map the similarities among ESs (at individual, community, and country scales) based on a non-metric multidimensional scaling (NMDS) ordination. We used a Spearman's rank correlation coefficient with 100 iterations and 25 restarts to minimize the stress value (Legendre \& Legendre 1998; Clarke \& Gorley 2006). This approach places services that respondents gave similar relative priorities close to one another and services that respondents gave different relative priorities far from one another. Third, we used the total ES priorities, determined in the ranking exercise, to map the similarities among ESs (at individual, community, and country scales) based on NMDS ordination. We used Spearman's rank correlation coefficient with 100 iterations and 25 restarts to minimize the stress value (Legendre \& Legendre 1998; Clarke \& Gorley 2006).

\section{Results}

\section{Human values underlying ES}

Fish workers from the western Indian Ocean identified a number of motivations (i.e., human values) associated with each ES. All motivations aligned with broader human values from social psychology and together covered the full spectrum of human value domains (Table 2) (Schwartz 1994, 2013). It was not possible to assign individual values to each ES because the motivations identified reflected multiple value types (e.g. power and achievement) (Supporting Information). However, the value types associated with each ES tended to fall into a single value domain (Schwartz 1994, 2013) (e.g., traditionalism, openness to change, self-transcendence, and self-enhancement) (Table 2). The exception was the ES recreation, where the stated motivations could be classified as openness to change (e.g., creative) or selfenhancement (e.g., wealth) values. However, because the identified self-enhancement values were yet to be realized by the respondent (i.e., they represented new opportunities to harness ecosystems for income), we assigned recreation to the openness-to-change value domain. Four groups of ESs were identified, each associated with a values domain: culture, education, and bequest associated with traditionalism values; recreation associated with openness-to-change values; fishery and materials associated with self-enhancement values; and habitat, coastal protection, and sanitation associated with selftranscendence values (Table 2).

\section{Ordering of ES priorities}

There were significant differences in the priorities assigned to the 9 ESs based on marginal $\left(F_{8,2984}=116\right.$, $p<0.0001)$ and total $\left(F_{8,2984}=92, p<0.001\right)$ estimates. There were 4 levels of priorities for marginal value estimates. Fishery was the highest priority and was followed by habitat and education; coastal protection, sanitation, and bequest; and, finally, materials, recreation, and culture (Fig. 2a). There was no difference in the LMM performance based on AIC values, suggesting this ordering was consistent across community, country, and region (Supporting Information). There were 7 levels of priority for total value estimates: fishery and habitat were the highest priority; education was second; coastal protection, third; sanitation, fourth; materials and bequest, fifth; recreation, sixth; and culture was the lowest priority (Supporting Information). Again, there was no difference in LMM performance based on AIC values, suggesting this ordering was also consistent across community, country, and region (Supporting Information).

The individual priorities assigned to ESs varied significantly for both marginal $\left(\mathrm{F}_{2,223}=733, p<0.0001\right)$ and total $\left(F_{2,247}=50, p<0.0001\right)$ estimates at country and community scales (Supporting Information). The greatest variability was associated with the largest marginal values $\left(R^{2}=0.79 ; \mathrm{P}<0.0001 ; \mathrm{F}_{1,34}=133.2\right)$ (Fig. 2b) and the smallest total values $\left(R^{2}=0.63 ; p<0.0001 ; F_{1,34}=57.4\right)$ (Fig. 2c). There was no difference in model performance based on AIC values, suggesting these relationships hold across scale (Supporting Information). In other words, although there tended to be agreement that fishery, habitat, and education were of high priority in general (total value), there was less agreement that improvements (marginal value) to fishery, habitat, and education were a high priority. 

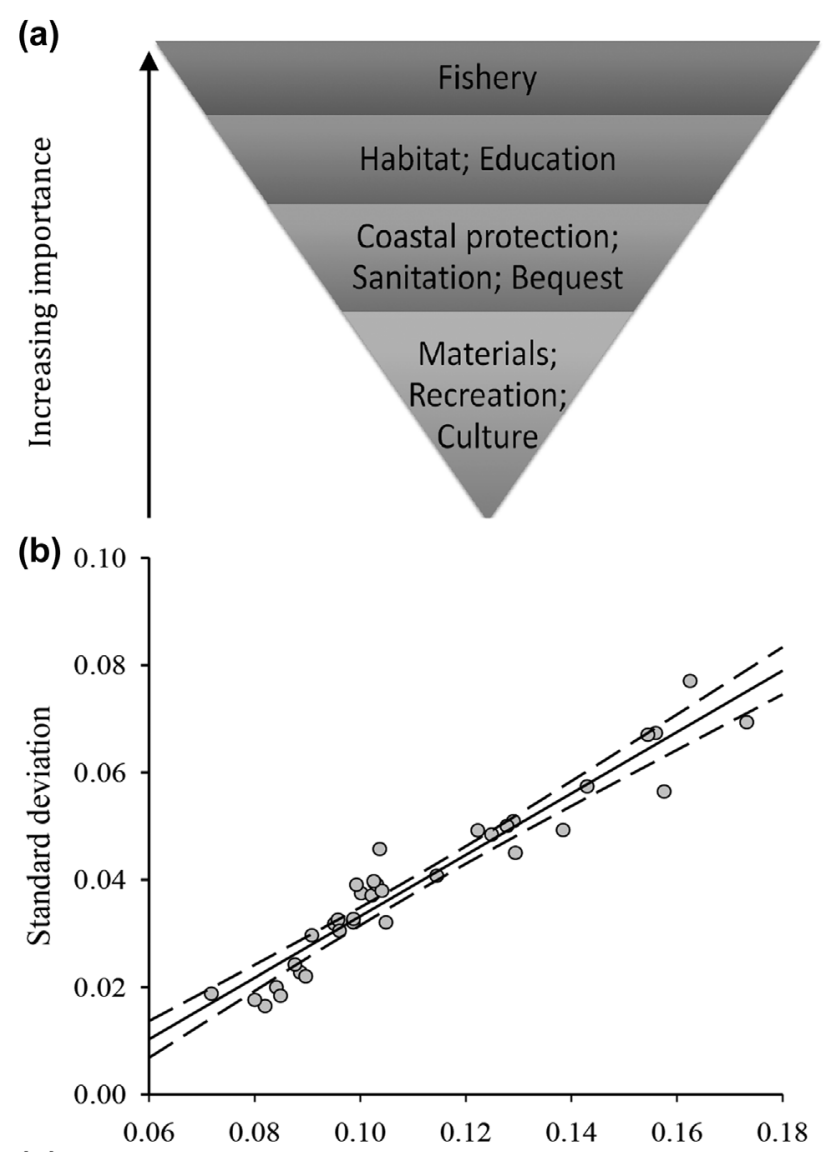

(c) Importance (normalized marginal value)

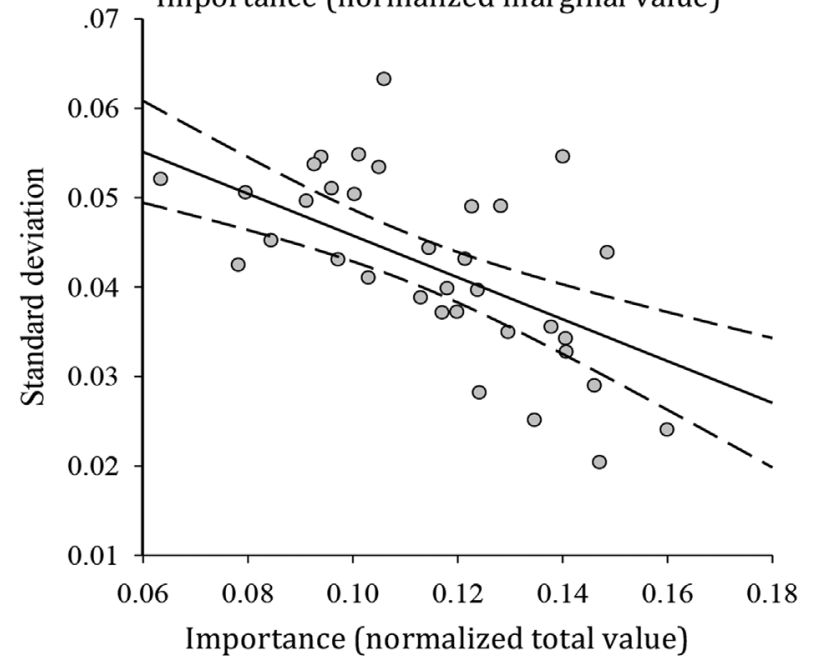

Figure 2. (a) Order of the mean marginal value people in western Indian Ocean countries place on each ecosystem service (ES) (layers reflect significant differences between mean values [based on linear mixed model]), (b) estimates of the marginal value respondents placed on each ES, and (c) estimates of the total value respondents placed on each ES (dots, average value assigned to each ES by each country [9 ESs in each of 4 countries]; dashed lines, 95\% CIs calculated around the slope).

\section{Relationships among ES}

All 3 ES approaches (human values, marginal, and total priorities) produced similar patterns that were consistent across scale. This result suggests ESs were related to one another in a consistent manner (Fig. 1; Supporting Information). Based on human values and marginal priorities, culture, education, and bequest were bundled and diagonally opposite recreation. This juxtaposition reflected a trade-off. Similarly, habitat, coastal protection, and sanitation were bundled and diagonally opposite a bundle composed of fishery and material, which reflected a second trade-off (Fig. 1). Bundling based on total value priorities was similar. The most notable difference was recreation's positioning adjacent to, rather than opposite, culture, education, and bequest (Supporting Information).

\section{Discussion}

Our results support 3 key findings. First, individual ESs were associated with multiple human values, but these values were all from the same value domain (Schwartz 2013). Second, certain ESs were consistently prioritized higher than others. Schwartz and Bardi (2001) and Fischer and Schwartz (2011) similarly found that certain human values are consistently prioritized higher than others. However, the consistency in ES priorities masked considerable, yet predictable, variation in individuals' priorities. Third, we found consistent patterns among ES priorities and their associated human values, reflecting synergies and trade-offs among ESs (Raudsepp-Hearne et al. 2012; Vira et al. 2012; Hicks et al. 2013). Together, these key findings hold promise for understanding when and why convergence and trade-offs in people's ES priorities occur. People's behavior can be influenced by the values they hold. An understanding of the motivations associated with people's priorities can therefore help managers develop locally appropriate policies (e.g., people motivated by a concern for others are more likely to co-operate and thus be amenable to co-management).

\section{Understanding ES preferences from their underlying human} values

Even in resource dependent societies, the state of natural resources is seldom a main priority (Mills et al. 2011). Instead, people use broad goals to prioritize their decisions and develop behavioral norms. Dialogues that recognize the breadth of benefits people gain from nature are therefore an important part of any conservation discussion. However, attempts to influence proenvironmental behavior need to be informed by people's psychological motivations. We found ES preferences were associated with a range of motivations; but for any single ES, these motivations were similar and within the 
same value domain (Davidov 2010). Future studies can therefore focus on identifying the value domain (e.g. selfenhancement), rather than the type of value (e.g., power) associated with an ES. Fishery benefits were, for example, associated with individual achievement, satisfaction, economic gain, and success (Schwartz 2009; Pollnac et al. 2012), whereas coastal protection benefits were associated with safe and reliable fishing environments and protected homes (Schwartz 2009). A single ES therefore influences multiple aspects of people's lives (Dietz et al. 2005).

\section{Consistent ordering of ES priorities and social heterogeneity}

The consistent pattern of ES prioritization (e.g., habitat, fishery, and education prioritized over materials, recreation, and culture) mirrors the human values literature, although details of the ordering differ (Schwartz \& Bardi 2001; Fischer \& Schwartz 2011). Furthermore, this pattern and order holds, whether considering ESs in general or an increase in ESs. However, the apparent consistency in ES priorities at community or country scale belies considerable variation that exists within a community. Importantly, this variation is greatest when an ES improvement is considered a high priority (e.g., fishery, education, and habitat). This pattern may arise because people prioritize only one value from fishery, habitat, and education, rather than all three simultaneously (Hicks et al. 2013). Disagreements are therefore likely to occur because groups of people have strong but differing opinions on which ESs need improvement.

There are many reasons why individuals may prioritize ESs differently. Different stakeholders often hold different priorities due to different occupations and experiences (Hicks et al. 2013). Similarly, individuals are only likely to perceive a benefit if they have access to and are capable of benefitting from a resource base (Leach et al. 1999; Hicks \& Cinner 2014). Standard processes of aggregation (e.g., means and medians) overshadow within-group variation and make assumptions about how individuals behave (Hitlin \& Piliavin 2004; Vatn 2009; Arrow 2012). Because there is no ideal or unique way to combine individual choices to obtain a group choice (Arrow 2012), future ES assessments should examine the distribution in individuals' priorities. If this variation is not attended to, any intervention is likely to benefit some and harm others, exacerbating existing inequalities and power asymmetries (Daw et al. 2011).

\section{Uncovering underlying mechanisms for ES synergies and trade-offs}

The arrangement of ESs into value domain broadly aligned with the 4 ES categories (MA 2003). Furthermore, this arrangement supported established trade-offs commonly reported in the ES literature, specifically, between pro- visioning services and regulating or supporting services (Foley et al. 2005; Rodriguez et al. 2006; Martin-Lopez et al. 2012). This suggests ES trade-offs arise when human values conflict, whereas synergies arise when values align (Schwartz \& Boehnke 2004). However, preferences for various cultural ESs were motivated by conflicting values: excitement and change versus tradition and stability. This division creates trade-offs between recreation and culture, education, or bequest (Hicks et al. 2009). Cultural services are therefore in need of better conceptualizations (Chan et al. 2012; Daniel et al. 2012), and ES assessments need to ensure that cultural services, other than recreation, are captured (Hicks 2011; Seppelt et al. 2011; Milcu et al. 2013). A failure to do this could result in traditionally sacred locations being inadvertently replaced with recreation benefits and conflict (McClanahan et al. 1997).

\section{Implications for management and anticipating human behavior}

The values people prioritize are central to their sense of self. As such, people are likely to respond positively to opportunities to attain those values (Schwartz 1996). Theory suggests that self-transcendence values promote cooperation for social benefits, whereas self-enhancement values promote personal gains (Schwartz 1996). Similarly, openness-to-change values promote independence and change, whereas traditionalism values promote social stability (Schwartz 1996). These insights, and knowledge of how ESs relate to them, can help managers anticipate how people are likely to respond to various conservation approaches. Individuals who, for example, prioritize ES associated with self-transcendence values (i.e., supporting and regulating services) are more likely to engage in collaborative approaches that focus on social benefits such as community conservation areas. Similarly, individuals who prioritize ES associated with traditionalism values (i.e., culture, education, and bequest) are more likely to engage in management that maintains or reinforces local traditions or practices - such as securing traditional tenure, protecting sacred areas, or legitimizing local efforts to exclude destructive practices (McClanahan et al. 1997).

However, activities that promote one value simultaneously threaten the opposing value, causing people to respond negatively to activities that promote values of a low priority and positively to activities that promote values of a high priority. Understanding the relationships among ES values and their trade-off characteristics can help managers anticipate behavior and develop appropriate strategies (Schwartz 1996). People who prioritize recreation, an openness-to-change value, may support a management innovation, such as gated trap technology (Mbaru \& McClanahan 2013), but people who prioritize culture, a traditionalism value, may find this innovation 
threatening. Similarly, people who prioritize fishery, a self-enhancement value, may comply with management that addresses individual returns, such as maximizing yields or building pride in the success of management, whereas those who prioritize habitat, a self transcendence value, may object to such approaches. This suggests it may not be possible to accommodate all stakeholder desires. For example, protecting biodiversity and enhancing fisheries may not be possible because these values, and thus behaviors, are in opposition to one another. However, in such instances, managers would be wise to embrace the social heterogeneity and target approaches to the individuals most likely to support them. In this way, a conservation project can address biodiversity and fisheries objectives with different strategies targeting different individuals, both in the same location.

\section{Future research directions}

Although ES assessments are yet to be adopted widely by managers, the push to use them should incorporate a human values dimension to aid in their success. We have demonstrated how insights from psychology have application in ES research and how the different domains of cognition can help practitioners understand when, why, and what types of synergies and trade-offs are likely to emerge (Rodriguez et al. 2006; Martin-Lopez et al. 2012; Vira et al. 2012). This approach should allow conservation professionals to be explicit about the losses, costs, and hard choices involved (McShane et al. 2010; Vira et al. 2012). However, values are unlikely to be static. The human values associated with an ESs may change through time, particularly if aspirations, such as deriving income through recreation (e.g., tourism), are realized, and will differ depending on context. Key questions of relevance to future research are the observed relationships between ESs consistent through time and across contexts? how do people benefit from their environment? what influences the values people hold? and how can individual values be aggregated to determine a social value?

\section{Acknowledgments}

This work was funded by the Western Indian Ocean Marine Science Association (WIOMSA) through the Marine Science for Management scheme (MASMA). Logistical support was provided by the Wildlife Conservation Society (WCS) Madagascar and the Seychelles Fishing Authority. J. Cinner and C. Hicks received funding from the Australian Research Council. Figure 1a, table 1, and supplementary Figure 1 were adapted from Schwartz (1994) permission number: 3636920850835 . Many thanks to C. Abunge, R. Charo, D. Julie, and R. Solovo in the field, to the many fishers who gave their time and knowledge, to K. Nash for statistical advice, and to N. Graham for comments on the manuscript. T.R. McClanahan was supported by the Wildlife Conservation Society through grants from the John D. and Catherine T. MacArthur and Tiffany Foundations during this period.

\section{Supporting Information}

Additional figures portraying Schwartz value wheel, NMDS ordinations at a community and country scale, and ES ranking based on total values (Appendix S1); additional methods on ES framework used, questionnaire used, photographs and descriptions of ES, and the weighted rating method (Appendix S2); and additional tables containing motivation statements and assignment and AIC values (Appendix S3) are available online. The authors are solely responsible for the content and functionality of these materials. Queries (other than absence of the material) should be directed to the corresponding author.

\section{Literature Cited}

Ajzen I. 1985. From intentions to actions: a theory of planned behavior. Pages 11-39 in Kuhl J, Beskmann J, editors. Action control: From cognition to behavior. Springer, New York.

Ajzen I. 1991. The theory of planned behavior. Organizational Behavior and Human Decision Processes 50:179-211.

Arrow KJ. 2012. Social choice and individual values. Volume 12. Yale University, New Haven, Connecticut.

Balvanera P, Pfisterer AB, Buchmann N, He J, Nakashizuka T, Raffaelli DSB. 2006. Quantifying the evidence for biodiversity effects on ecosystem functioning and services. Ecology Letters 9:1146-1156.

Barnosky AD, et al. 2012. Approaching a state shift in Earth's biosphere. Nature 486:52-58.

Bateman IJ, et al. 2002. Economic valuation with stated preference techniques: a manual. Edward Edgar, Cheltenham.

Bateman IJ, et al. 2013. Bringing ecosystem services into economic decision-making: land use in the United Kingdom. Science 341:4550.

Böhnke-Henrichs A, Baulcomb C, Koss R, Hussain SS, deGroot RS. 2013. Typology and indicators of ecosystem services for marine spatial planning and management. Journal of Environmental Management 130:135-145.

Chan K, Satterfield T, Goldstein G. 2012. Rethinking ecosystem services to better address and navigate cultural values. Ecological Economics 74:8-18.

Clarke KR, Gorley RN. 2006. Primer v6:User Manual/Tutorial. PRIMERE, Plymouth. pp. 190.

COP (Convention on Biological Diversity). 2011. Report of the tenth meeting of the conference of the parties to the convention on biological diversity. (UNEP, Nairobi) pp.353.

Costello C, Ovando D, Hilborn R, Gaines SD, Deschenes O, Lester SE. 2012. Status and solutions for the world's unassessed fisheries. Science 338:517-520.

Daily GC, editor. 1997. Nature's services: societal dependence on natural ecosystems. Island Press, Washington D.C. pp.392.

Daily GC, Matson PA. 2008. Ecosystem services: From theory to implementation. Proceedings of the National Academy of Sciences 105:9455-9456. 
Daniel TC, et al. 2012. Contributions of cultural services to the ecosystem services agenda. Proceedings of the National Academy of Sciences 109:8812-8819.

Davidov E. 2010. Testing for comparability of human values across countries and time with the third round of the European Social Survey. International Journal of Comparative Sociology 51:171191

Daw T, Brown K, Rosendo S, Pomeroy R. 2011. Applying the ecosystem services concept to poverty alleviation: the need to disaggregate human well-being. Environmental Conservation 38:370-379.

Dietz T, Fitzgerald A, Shwom R. 2005. Environmental values. Annual Review of Environmental Resources 30:335-372.

Field AP. 2009. Discovering statistics using SPSS: (and sex and drugs and rock 'n' roll). Sage, London.

Fischer R, Schwartz S. 2011. Whence differences in value priorities? Individual, cultural, or artifactual sources. Journal of Cross-Cultural Psychology 42:1127-1144.

Foley JA, et al. 2005. Global consequences of land use. Science 309:570574.

Hicks CC, Cinner JE. 2014. Social, Institutional, and knowledge mechanisms mediate diverse ecosystem services from coral reefs Proceedings of the National Academy of Sciences, USA 111:17791-17796.

Hicks CC. 2011. How do we value our reefs? Risks and tradeoffs across scales in "biomass-based economies". Coastal Management 39:358376.

Hicks CC, Graham NAJ, Cinner JE. 2013. Synergies and tradeoffs in how managers, scientists, and fishers value coral reef ecosystem services. Global Environmental Change 23:1444-1453

Hicks CC, McClanahan TR, Cinner JE, Hills J. 2009. Trade-offs in values assigned to ecological goods and services associated with different coral reef management strategies. Ecology and Society 14:http://www.ecologyandsociety.org/vol14/iss1/art10/.

Hitlin S, Piliavin JA. 2004. Values: reviving a dormant concept. Annual Review of Sociology 30:359-393.

Hofstede G. 2011. Dimensionalizing cultures: the Hofstede model in context. Online Readings in Psychology and Culture 2(1):http://dx.doi.org/10.9707/2307-0919.1014

Leach M, Mearns R, Scoones I. 1999. Environmental entitlements: dynamics and institutions in community-based natural resource management. World development 27:225-247.

Legendre P, Legendre L. 1998. Numerical Ecology. 2nd edition. Elsevier Science, Amsterdam.

MA (Millennium Ecosystem Assessment). 2003. Ecosystems and human well-being: a framework for assessment. Island Press, Washington, D.C.

Maas CJM, Hox JJ. 2004. The influence of violations of assumptions on multilevel parameter estimates and their standard errors. Computational Statistics \& Data Analysis 46:427-440.

Mace GM, Norris K, Fitter AH. 2011. Biodiversity and ecosystem services: a multilayered relationship. Trends in Ecology \& Evolution 27:19-26.

Manfredo M, Teel T, Zinn HC. 2009. Understanding global values towards wildlife. Pages 31-43 in Manfredo M, Vaske J, Brown PJ, Decker DJ, Duke EA. editors. Wildlife and society: The science of human dimensions. Island Press, Washington, D.C.

Martín-López B, et al. 2012. Uncovering ecosystem service bundles through social preferences. PLOS ONE 7 (e38970) DOI: 10.1371/journal.pone.0038970.

Mastrangelo ME, Gavin MC, Laterra P, Linklater WL, Milfont TL. 2014. Psycho-social factors influencing forest conservation intentions on the agricultural frontier. Conservation Letters 7:103-110.

Mbaru EK, McClanahan TR. 2013. Escape gaps in African basket traps reduce bycatch while increasing body sizes and incomes in a heavily fished reef lagoon. Fisheries Research 148:90-99.

McClanahan TR, Glaesel H, Rubens J, Kiambo R. 1997. The effects of traditional fisheries management on fisheries yields and the coral- reef ecosystems of southern Kenya. Environmental Conservation 24:105-120.

McShane TO, et al. 2010. Hard choices: Making trade-offs between biodiversity conservation and human well-being. Biological Conservation 144:966-972.

Milcu AI, Hanspach J, Abson D, Fischer J. 2013. Cultural ecosystem services: a literature review and prospects for future research. Ecology \& Society 18: http://dx.doi.org/10.5751/ES-05790180344

Mills D, et al. 2011. Vulnerability in African small-scale fishing communities. Journal of International Development 23:308-313.

Milner-Gulland EJ. 2012. Interactions between human behaviour and ecological systems. Philosophical Transactions of the Royal Society B: Biological Sciences 367:270-278.

Morris CW. 1956. Varieties of human value. University of Chicago Press, Chicago. Pages 208.

Norgaard RB. 2010. Ecosystem services: From eye-opening metaphor to complexity blinder. Ecological Economics 69:1219-1227.

Pearce DW, Turner RK. 1989. Economics of natural resources and the environment. Johns Hopkins University Press, Baltimore, MD.

Pollnac R, Bavinck M, Monnereau I. 2012. Job satisfaction in fisheries compared. Social Indicators Research 109:119-133.

Raudsepp-Hearne C, Peterson GD, Bennett EM. 2010. Ecosystem service bundles for analysing trade-offs in diverse landscapes. Proceedings of the National Academy of Sciences 107:5242-5247.

Rodríguez JT, Beard D Jr, Bennett EM, Cumming GS, Cork SJ, Agard J, Dobson AP, Peterson GD. 2006. Trade-offs across space, time, and ecosystem services. Ecology and Society 11: http://www.ecologyandsociety.org/vol11/iss1/art28/

Rokeach M. 1973. The nature of human values. Free Press, New York.

Rokeach M. 2008. Understanding human values. Free Press, New York.

Schwartz SH. 1996 Value priorities and behavior: applying a theory of integrated value systems. Erlbaum L. editor. The psychology of values. The Ontario Symposium, Vol 8.

Schwartz SH. 1994. Are there universal aspects in the structure and contents of human values? Journal of Social Issues 50:19-45.

Schwartz SH. 2009. Draft users manual: proper use of the Schwartz Value Survey, compiled by Romie F. Littrell. Centre for cross cultural comparisons, Auckland, New Zealand. Available from http://www.crossculturalcentre.homestead.com

Schwartz SH. 2013. The psychology of values. Pages 1-23 in C Seligman, C. J. M. Olson and M. P. Zanna editors. The Ontario Symposium 8. Psychology Press, Ontario.

Schwartz SH, Bardi A. 2001. Value hierarchies across cultures taking a similarities perspective. Journal of Cross-Cultural Psychology 32:268-290

Schwartz SH, Boehnke K. 2004. Evaluating the structure of human values with confirmatory factor analysis. Journal of Research in Personality 38:230-255

Seppelt R, Dormann CF, Eppink FV, Lautenbach S, Schmidt S. 2011. A quantitative review of ecosystem service studies: approaches, shortcomings and the road ahead. Journal of Applied Ecology 48:630-636.

Song AM, Chuenpagdee R, Jentoft S. 2013. Values, images, and principles: What they represent and how they may improve fisheries governance. Marine Policy 40:167-175.

Stern PC, Dietz T, Abel T, Guagnano GA, Kalof L. 1999. A valuebeliefnorm theory of support for social movements: the case of environmentalism. Research in Human Ecology 6:81-97.

Tetlock PE. 1986. A value pluralism model of ideological reasoning. Journal of Personality and Social Psychology 50:819-827.

Vatn A. 2009. An institutional analysis of methods for environmental appraisal. Ecological Economics 68:2207-2215.

Vira B, Adams B, Agarwal C, Badiger S, Hope RA, Krishnaswamy J, Kumar C. 2012. Negotiating trade-offs: Choices about ecosystem services for poverty alleviation. Economic \& Political Weekly 47:6775 . 